\title{
The Mental Health and Sleep Quality of the Medical Staff at a Hub-Hospital against COVID-19 in South Korea
}

\author{
Doo Hyuk Kwon ${ }^{1}$, Jihye Hwang ${ }^{1}$, Yong Won Cho ${ }^{1}$, Mei Ling Song ${ }^{2}$, Keun Tae Kim ${ }^{1}$ \\ ${ }^{1}$ Department of Neurology, Keimyung University School of Medicine, Daegu, \\ ${ }^{2}$ Department of Nursing Science, College of Nursing, Daegu Health College, Daegu, Korea \\ COVID-19 거점 병원 의료진의 수면과 정신 건강 조사
}

권두혁, 황지혜 ${ }^{1}$, 조용원 ${ }^{1}$, 송미령 ${ }^{2}$, 김근태 ${ }^{1}$

계명대학교 의과대학 신경과학교실, ${ }^{1}$ 대구보건대학교 간호대학 간호학교실 ${ }^{2}$

\section{Received June 3, 2020 \\ Revised June 11,2020 \\ Accepted June 12, 2020}

Address for correspondence

Keun Tae Kim, MD

Department of Neurology,

Keimyung University

School of Medicine,

1095 Dalgubeol-daero,

Dalseo-gu, Daegu 42601, Korea

Tel: +82-53-258-4379

Fax: $+82-53-258-4380$

E-mail:6k5upa@gmail.com
Objectives: Now, coronavirus disease (COVID-19) is worldwide threatening. Medical staff's efforts and sacrifices against COVID-19 are still ongoing. The purpose of this study was to investigate the mental health of the medical staff who have fought against the COVID-19 in hub hospitals. Methods: The medical staff underwent an evaluation of psychiatric and sleep status between March 23rd and April 3rd, 2020. Based on the evaluation, we retrospectively analyzed depression, anxiety, and sleep quality of the medical staff, who worked more than 7 days for fighting against the COVID-19. Results: This study included a total of 101 medical staff. Approximately 1/4 of the medical staff showed depressive mood and low quality of sleep, and more than $1 / 3$ reported anxiety. The nurses reported more severe psychiatric symptoms and poorer sleep quality. Conclusions: This study demonstrated the mental and sleep status of the medical staff against COVID-19. Medical and social support should be considered for them.

J Sleep Med 2020;17(1):93-97

\section{서 론}

2020년 1월 19일, 대한민국에서 첫 번째 코로나바이러스 감염증-19(coronavirus disease, COVID-19) 환자가 발생하 였다. ${ }^{1}$ 그리고 2020년 6월 2일 현재, 우리나라의 COVID-19 확진 환자는 11,541 명이며, 사망자는 272 명이다. ${ }^{2}$ 이 중에서 대구-경북 지역의 확진자는 8,263명으로 우리나라 전체 누적 확진 환자의 약 $72 \%$ 에 해당한다. ${ }^{2}$ 계명대학교 대구동산병원 (Keimyung University Daegu Dongsan Hospital, DDH)은 2020년 2월 21일부터 대구-경북 지역의 COVID-19 거점 병 원으로 지정되었다.

우리나라에서 발생했던 대대적인 감염성 질환으로는 2015 년에 있었던 Middle East respiratory syndrome-coronavirus

This is an Open Access article distributed under the terms of the Creative Commons Attribution Non-Commercial License (https://creativecommons.org/licenses/by-nc/4.0) which permits unrestricted non-commercial use, distribution, and reproduction in any medium, provided the original work is properly cited.
(MERS-CoV)가 있는데, 현재까지의 경과로 보아 COVID-19는 더 강력한 감염력을 가진 것으로 보인다. ${ }^{3}$ 이에 우리 나라 정부는 사회적 거리 두기, 손씻기, 마스크 착용 등의 수 칙을 제시하고 감염을 최소화하기 위해 노력하고 있다. 확진 환자 발생 숫자가 많이 감소했으나 세계적으로는 환자 수가 계속해 증가하여 200만 명을 넘어선 상황이고 확진자와 사망 자는 꾸준히 증가하고 있는 상태이다. ${ }^{4}$ 백신 및 치료제가 개 발되지 않은 상태에서 국내에서도 2차적인 팬데믹 발생에 대 한 불안감은 지속되고 있다. 새로운 환자가 꾸준히 발생한다 는 것은 의료 인력의 지속적인 필요를 뜻한다. 현재 운영 중인 COVID-19 거점 병원(병원 전체 건물을 COVID-19 환자만 수용하고 치료하도록 함)은 교체 또는 대체가 어려운 가운데, 고병원성 감염 질환의 진료에 투입되는 의사와 간호사의 육 체적, 심리적 부담에 대해서 평가하고 확인할 필요가 있다.5,6

고위험성 감염 질환의 특성상 환자는 격리 치료가 필요하 며, 이를 돌보는 의료진도 감염 위험에 노출된다. ${ }^{7}$ 이에 따라 
방호복과 마스크 등을 착용하고 진료를 하는데, 이러한 보호 구에 의하여 의료진의 육체적 피로도가 심한 것으로 알려져 있다. 게다가 고위험성 감염 질환자의 진료는 필연적으로 감 염에 대한 위험을 동반하기 때문에, 환자뿐만 아니라 의료진 도 감염과 격리에 대한 심한 스트레스를 느낀다. ${ }^{89}$ Xiang 등 은 COVID-19로 인한 심리적 건강의 악화 가능성을 지적하 였으며, 여러 가지 상담의 필요성에 대해서 제안한 바가 있 다. ${ }^{5}$ 하지만 현재 우리나라에서 시행 중인 지원 방안과 정책 등은 COVID-19 환자에 초점이 맞춰져 있으며, 의료진에 대 한 조사나 의료진의 육체적 또는 심리적 문제에 대해서는 아 무런 정책이나 대응이 없는 실정이다. 이에 본 연구진은 $\mathrm{DDH}$ 에서 의사와 간호사의 우울과 불안, 그리고 수면의 질을 평가 한 자료를 바탕으로 COVID-19 대응팀에 참여한 의료진의 수면과 정신 건강에 대하여 분석하였다.

\section{방 법}

$\mathrm{DDH}$ 에서는 COVID-19 진료에 참여한 의사와 간호사의 정신 건강을 위하여, 근무 일수가 7일 이상인 대상자 총 101 명을 대상으로 2020년 3월 23일부터 2020년 4월 3일까지 2 주에 걸쳐서 우울과 불안, 수면에 대한 척도 검사와 함께 면 담이 진행되었다. 본 연구는 이 면담에서 사용된 우울, 불안, 그리고 수면에 대한 척도 검사 결과를 바탕으로 후향적 단면 조사연구를 시행하였으며, 평가 도구에 기입된 의료인의 나 이, 성별, 근무 기간, $\mathrm{DDH}$ 에의 참여 경로, 직종(의사 또는 간 호사)을 확인하였다.

\section{우 울}

본 연구에서는 Beck 등에 의하여 개발된 우울 측정 도구를 $\mathrm{Lim}$ 등이 한글로 번안하여 타당도를 검증한 Beck depression inventory-II(BDI) 도구를 사용하였다. 10,11 $\mathrm{BDI}$ 는 지난 2 주간의 증상을 평가하는 도구로써 총 21문항으로 구성되었 으며 각 문항은 0 3점까지의 4단계의 리커트 척도(Likert scale)로 평가한다. 총점은 0 63점으로, 점수가 높을수록 우 울 상태가 더욱 심함을 나타내며 총점이 14점 이상이면 유의 미한 우울로 간주하였다.

\section{불 안}

본 연구에서 사용한 불안 평가 도구는 Beck anxiety inventory(BAI)로써, Beck 등이 개발하였고 Yook과 Kim이 한글 로 번안하여 타당도를 검증하였다. ${ }^{12,13} \mathrm{BAI}$ 는 총 21 개 문항 으로 구성되었으며 각 문항은 0점(전혀 느끼지 않았다)에서 3점(심하게 느꼈다)까지 4단계의 Likert 척도로 평정하도록
되어 있다. 총점은 0점에서 63점이며 점수가 높을수록 불안 이 더욱 높음을 의미하며 총점이 8점 이상인 경우 의미 있는 불안이 있는 것으로 간주하였다.

\section{수면의 질}

수면의 질은 Buysse 등이 개발하고 Sohn 등이 한글로 번 안하여 타당도 검증을 거친 Pittsburgh sleep quality index (PSQI) 도구를 사용하였다..$^{14,15} \mathrm{PSQI}$ 는 수면의 질, 수면 개시 시 잠복기, 수면 시간, 수면 효율, 수면 방해, 수면 관련 약물 의 사용과 주간 기능장애와 관련된 18 문항으로 이루어져 있 다. 총점은 21점으로 점수가 높을수록 수면의 질이 낮아짐을 의미하며 총점이 9점 이상일 경우 수면의 질이 의미 있는 정 도로 나쁜 것으로 간주하였다.

\section{통계 분석}

본 연구에서 수집된 자료는 SPSS version 22.0 통계 분석 프로그램(IBM Corp., Armonk, NY, USA)을 사용하여 분석 하였으며, 결과의 통계적 유의성은 기본적으로 양측 유의 수 준 5\% 이하에서 판단하였다. 일반적 특성, 우울, 불안, 수면 의 질과 관련된 분석은 평균 및 빈도 분석으로 하였으며, 간 호사와 의사의 그룹 간 비교에서 질적 자료는 $\chi^{2}$-test, 양적 자료는 t-test로 분석하였다. 본 연구는 자료 수집에 앞서 지 역의 한 상급 종합병원의 기관생명윤리위원회의 승인을 받 았으며(IRB No. DSMC 2020-04-008), 후향적 연구 설계로 서면 동의는 면제되었다.

\section{결 과}

거점 병원으로 지정된 후부터 DDH는 오로지 COVID-19 환자만을 대상으로 입원 치료를 시행하였으며, 전체 재원 환 자 수는 약 380명에서 400명을 꾸준하게 유지하는 가운데 하 루에 30 50명의 입퇴원 환자가 발생하였다. 의사는 휴일 없 이 하루 10시간 근무하며, 일주일에 2 3회는 4 5시간의 추 가 근무를 하였다. 간호사는 2 시간 근무, 2 시간 휴식, 그리고 2시간 근무의 방식으로 교대 근무를 하였다. $\mathrm{DDH}$ 에서 1 주 일 이상 근무한 의사와 간호사는 각각 약 50여 명과 140여 명이었는데, 이 중에서 의사 47 명과 간호사 54 명이 면담과 조사에 응하였다.

\section{대상자의 특성}

연구 기간 동안에 면담과 조사에 응한 대상자는 118 명이 었으며, 이 중 7일 이상 근무한 101명에 대해서 분석을 시행 하였다. 분석에 포함된 인원 중에서 의사와 간호사는 각각 
47명과 54명이었다. 평균 나이는 $34.73 \pm 9.36$ 세였으며, 여성 이 67명(66.34\%)이었다. 의사는 47명(46.5\%), 간호사는 54명 (53.5\%)였으며, COVID-19 대응팀으로서 $\mathrm{DDH}$ 에서 근무한 평균 기간은 약 15 일(15.27 \pm 7.73$)$ 이었다(Table 1).

\section{우울, 불안, 그리고 수면의 질}

전체 대상자의 우울, 불안, 그리고 수면의 질은 설문지로 평가하였으며, 그 결과는 Table 2 와 같다. $\mathrm{BDI}$ 의 평균 점수 는 9.89 8.80 이었으며, 24 명(23.76\%)에서 우울감을 의심할 수 있었다. BAI의 평균 점수는 7.79 \pm 8.71 이었으며, 36 명(35.64\%) 에서 임상적으로 의미 있는 불안감이 있었다. PSQI의 평균 점 수는 $6.61 \pm 3.07$ 이었으며, 26 명 $(25.74 \%)$ 에서 수면의 질이 떨 어져 있었다(Table 2).

\section{의사와 간호사의 비교}

의사 47 명과 간호사 54 명의 평균 연령은 각각 $35.41 \pm 7.40$ 세와 $34.13 \pm 10.85$ 세로서 차이가 없었으며, 평균 근무 일수는 각각 $16.36 \pm 7.01$ 일과 $14.31 \pm 8.25$ 일로 또한 통계적인 차이가 없었다. 의사는 자원봉사자나 파견의 형태 $(25,53.19 \%)$ 가 $\mathrm{DDH}$ 에 소속되어 근무하는 경우(22, 46.81\%)보다 많았고, 간 호사도 자원봉사자나 파견의 형태 $(35,64.81 \%)$ 로 근무하는 경 우가 DDH에 소속된 경우(19,35.19\%)보다 많았으며, 그 비율 은 의사와 간호사 사이에 차이가 없었다 $(p=0.26)$. 의사와 간 호사의 $\mathrm{BDI}, \mathrm{BAI}$, 그리고 $\mathrm{PSQI}$ 평균 점수는 각각 $6.98 \pm 6.39$ vs. $12.43 \pm 9.83(p=0.001), 5.00 \pm 6.97$ vs. $10.22 \pm 9.38(p=0.002)$,

Table 1. Demographic data of the medical staff at the hub-hospital against COVID-19 $(n=101)$

\begin{tabular}{lc}
\hline & $\begin{array}{c}\text { Mean } \pm \text { SD or } \\
\text { number }(\%)\end{array}$ \\
\hline Age (years) & $34.73 \pm 9.36$ \\
Sex (female) & $67(66.34)$ \\
Days working at Daegu Dongsan Hospital (days) & $15.27 \pm 7.73$ \\
Faculty of Daegu Dongsan Hospital & $41(40.59)$ \\
Occupation & \\
$\quad$ Doctor & $47(46.53)$ \\
$\quad$ Nurse & $54(53.47)$ \\
\hline COVID-19: coronavirus disease, SD: standard deviation
\end{tabular}

$5.11 \pm 2.25$ vs. $7.96 \pm 3.11(p<0.001)$ 로서, 모든 부문에서 간 호사의 점수가 높았다(Fig. 1, Table 3). 이 중에서 BDI의 절 단 값보다 높은 점수를 보여준 대상자는 의사와 간호사에서 각각 9명(19.15\%)과 15명(27.78\%)으로서 통계적인 차이는 없었지만 $(p=0.310), \mathrm{BAI}$ 에서는 각각 11 명(23.40\%)과 25명 (46.30\%)으로서 간호사가 더 많았다( $p=0.017)$. 또한 PSQI에 서는 각각 4 명 $(8.51 \%)$ 과 22 명(40.74\%)으로서 간호사에서 수 면의 질이 나쁜 경우가 더 많았다 $(p<0.001)$ (Table 3$)$.

\section{고 찰}

본 연구는 COVID-19 거점 병원에서 근무한 의사와 간호 사를 대상으로 우울과 불안, 그리고 수면의 질에 대해서 조 사하였다. COVID-19 대응팀으로 근무한 의료인은 높은 우 울과 불안, 낮은 수면의 질을 보고하였으며, 특히 간호사가 의사보다 심한 것을 확인하였다.

중증급성호흡기증후군(severe acute respiratory syndrome) 이 발생했던 2004년에 캐나다의 보고에서는, 관련 의료 종사 자의 약 $90 \%$ 가 급성 심리 증상을 보고했다. ${ }^{16}$ 한편 최근의 보 고에 따르면 2015년에 MERS-CoV에 대한 진료 업무를 수 행한 의료진은 수 년의 시간이 흘렀음에도 불구하고 외상후 스트레스증후군을 보일 위험이 높다는 것을 확인하였다. ${ }^{17}$ 이번 COVID-19와 관련하여 중국의 연구에 따르면, 관련된 진료 업무에 종사한 의료진 중에서 약 $1 / 2$ 의 의료진에서 우 울감과 불안감이, 약 $1 / 3$ 의 의료진에서 불면증이 보고되었

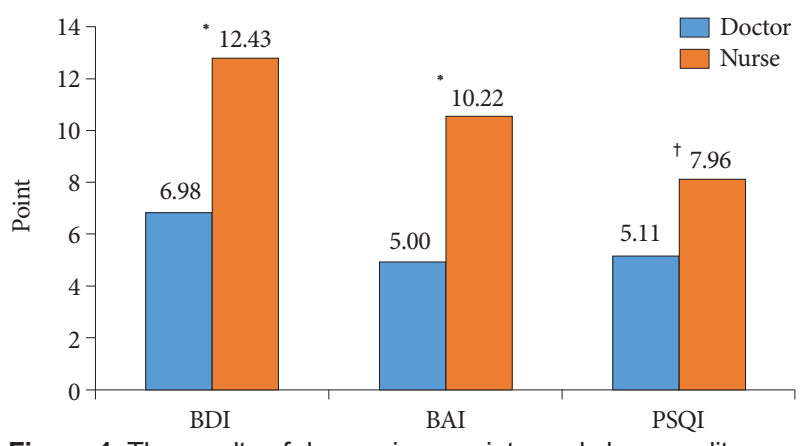

Figure 1. The results of depression, anxiety, and sleep quality survey for the medical staff. ${ }^{*} p=0.001,{ }^{t} p<0.001$. BDI: Beck depression inventory-II, BAI: Beck anxiety inventory, PSQI: Pittsburgh sleep quality index.

Table 2. Depression, anxiety, and poor sleep quality of the medical staff

\begin{tabular}{cccc}
\hline Questionnaire & Average score \pm SD & Cut-off value & Numbers of subjects over cut-off (n, \%) \\
\hline BDI & $9.89 \pm 8.80$ & $\geq 14$ & $24(23.76)$ \\
BAI & $7.79 \pm 8.71$ & $\geq 8$ & $36(35.64)$ \\
PSQI & $6.61 \pm 3.07$ & $\geq 9$ & $26(25.74)$ \\
\hline
\end{tabular}

BDI: Beck depression inventory-II, BAI: Beck anxiety inventory, PSQI: Pittsburgh sleep quality index, SD: standard deviation 
Table 3. Comparison of the demographic data, mental health, and sleep quality of the doctors and nurses

\begin{tabular}{|c|c|c|c|c|}
\hline & Doctor $(n=47)$ & Nurse $(n=54)$ & $\chi^{2} / t$ & $p$ \\
\hline Age (years) & $35.41 \pm 7.40$ & $34.13 \pm 10.85$ & 0.68 & 0.497 \\
\hline Days of service (days) & $16.36 \pm 7.01$ & $14.31 \pm 8.25$ & 1.33 & 0.186 \\
\hline Ways to participate in Daegu Dongsan Hospital (n, \%) & & & 32.03 & $<0.001$ \\
\hline Faculty of Daegu Dongsan Hospital & $22(46.81)$ & $19(35.19)$ & & \\
\hline Volunteered or dispatched & $25(53.19)$ & $35(64.81)$ & & \\
\hline BDI (average score) & $6.98 \pm 6.39$ & $12.43 \pm 9.83$ & -3.34 & 0.001 \\
\hline $\mathrm{BDI} \geq 14$ (number of subjects over cut-off) & $9(19.15)$ & $15(27.78)$ & 1.03 & 0.310 \\
\hline BAI (average score) & $5.00 \pm 6.97$ & $10.22 \pm 9.38$ & -3.20 & 0.002 \\
\hline $\mathrm{BAI} \geq 8$ (number of subjects over cut-off) & $11(23.40)$ & $25(46.30)$ & 5.74 & 0.017 \\
\hline PSQI (average score) & $5.11 \pm 2.25$ & $7.96 \pm 3.11$ & -5.28 & $<0.001$ \\
\hline PSQI $\geq 9$ (number of subjects over cut-off) & $4(8.51)$ & $22(40.74)$ & 14.56 & $<0.001$ \\
\hline
\end{tabular}

BDI: Beck depression inventory-II, BAI: Beck anxiety inventory, PSQI: Pittsburgh sleep quality index

다. ${ }^{18}$ 본 연구에서도 분석에 포함된 전체 의료인 중에서 우울 과 수면장애를 보고한 것은 각각 약 $1 / 4$ 이었으며, 불안감은 약 $1 / 3$ 의 의료진이 보고하였다.

환자의 진료에서 의사와 간호사는 중추적 역할을 담당하 며 상호 보완적인 관계이다. 본 연구에서는 전체 의료진에서 심리적 상태와 수면의 질에 대한 평가를 시행한 결과를 바탕 으로, 의사와 간호사에 대해서 직군별로 심리 상태를 비교하 였다. 그 결과 간호사에서 우울, 불안, 수면의 질 저하가 의사 보다 더 나쁜 상태를 확인하였다. 이전에 발표된 감염성 질환 관련 연구에서 의사에 비하여 간호사의 심리적 부담이 더 심 한 것으로 꾸준히 보고된 것과 일치하는 소견이다. ${ }^{19-21}$ 본 연 구에서 분석한 자료만으로는 그 원인에 대해서 자세히 알 수 는 없다. $\mathrm{DDH}$ 에서는 의사의 경우 감염성 호흡기 질환을 주 로 다루지 않던 외과, 안과, 응급의학과, 신경과 등의 다양한 전문의가 하루 9 10시간 근무하고 일주일에 2일 이상은 초 과 근무를 하였고, 간호사는 2시간 근무-2시간 휴식-2시간 근무로 이루어진 스케줄을 소화함으로써 바쁘게 움직였다. 또한 우리나라에서 COVID-19에 대한 질병 관련 지식이나 제공되는 의료 장비에서 차이가 나지는 않을 것으로 사료되 므로 이전의 연구에서 거론된 것 외에 다른 요인을 고려할 필 요가 있다. 이전의 연구에서는 고위험성 감염 질환의 진료에 서 간호사의 우울과 불안의 정도가 높은 원인에 대해서 감염 원에 대한 보호 장구의 부족이나 감염 환자에 대한 근접 근 무, 긴 근무 시간 등의 요인을 거론하였는데, ${ }^{20,21}$ 본 연구에 사 용된 면담 결과가 만들어질 때까지는 $\mathrm{DDH}$ 에서 보호 장구의 지급에 부족이 없었기 때문에 장비 부족의 영향은 없었다고 사료된다. 하지만 간호사가 의사에 비하여 환자에 대한 근접 근무의 비율이 많은 점, 일주기 리듬에 영향을 받을 수 있는 스케줄로 교대 근무를 하는 점이 작용했을 것으로 사료된다.
본 연구에는 몇 가지 제한점이 있다. 첫째, 단일 병원에서 7일 이상의 기간 동안 COVID-19 관련 진료에 참여한 의료 진만 대상으로 후향적으로 분석하였기 때문에 선택 편향을 배제할 수 없다. 둘째, 전국 각지에서 의사와 간호사들이 지 원하여 COVID-19 거점 병원에 오게 되었으며, 또한 사회적 관심과 배려와 지원이 있었다. 그러나 본 연구에서는 출신 지역이나 COVID-19 거점 병원에 근무하는 이유(DDH 소 속의 의료인, 자원봉사, 병역 등)에 의한 영향이 고려되지 않 았다. 셋째, 의료인 개인의 사명감이 심리적 건강에 상당한 영 향을 줄 가능성이 높지만 이에 의한 영향이 고려되지 않았다. 그럼에도 불구하고 본 연구는 우리나라에서 COVID-19 진료 에 참여한 의료인의 심리적 건강과 수면의 질에 대한 첫 번째 연구로서, COVID-19 진료를 위한 의료진을 구성하고 운영 및 유지하는 데에 중요한 참고 자료가 될 것이다.

결론적으로 COVID-19에 관련한 진료에서 비록 의사와 간호사는 함께 일하고 있지만, 정신 건강 상태와 수면의 질은 간호사가 의사보다 취약하다. 아직 끝나지 않은 COVID-19 와의 싸움에서 의료진의 정신 건강 상태에 대한 관심과 배려 가 필요하며, 역할에 따른 차이가 있음을 염두에 두고 의료 진의 정신 건강에 대해서 접근할 필요가 있겠다.

\section{Acknowledgments}

This study was supported by a research grant from Daegu Medical Association COVID-19 scientific committee.

\section{Conflicts of Interest}

The authors have no potential conflicts of interest to disclose.

\section{ORCID iDs}

Doo Hyuk Kwon Jihye Hwang Yong Won Cho

https://orcid.org/0000-0001-7541-9226 https://orcid.org/0000-0002-8736-6309 https://orcid.org/0000-0002-6127-1045 
Mei Ling Song

Keun Tae Kim

https://orcid.org/0000-0002-4903-9067

https://orcid.org/0000-0002-7124-0736

\section{Author Contributions}

Conceptualization or/and Methodology: Doo Hyuk Kwon, Keun Tae Kim. Data curation or/and Analysis: Doo Hyuk Kwon, Keun Tae Kim, Mei Ling Song. Investigation: Doo Hyuk Kwon, Jihye Hwang. Project administration or/and Supervision: Keun Tae Kim, Mei Ling Song. Resources or/ and Software: Doo Hyuk Kwon, Yong Won Cho. Validation: Yong Won Cho, Keun Tae Kim. Visualization: Yong Won Cho, Keun Tae Kim. Writingoriginal draft: Doo Hyuk Kwon. Writing — review \& editing: all authors.

\section{REFERENCES}

1. Kim JY, Choe PG, Oh Y, et al. The first case of 2019 novel coronavirus pneumonia imported into Korea from Wuhan, China: implication for infection prevention and control measures. J Korean Med Sci 2020; 35:e61.

2. Cases in Korea by city/province. Ministry of Health and Welfare, 2020. [cited 2020 Apr 26]. URL: http://ncov.mohw.go.kr/en/bdBoardList.do? brdId $=16 \&$ brdGubun $=162 \&$ dataGubun $=\&$ ncvContSeq $=\& \operatorname{contSeq}=\&$ board_id=.

3. Jeong EK, Park O, Park YJ, et al.; COVID-19 National Emergency Response Center, Epidemiology and Case Management Team, Korea Centers for Disease Control and Prevention. Coronavirus disease-19: the first 7,755 cases in the Republic of Korea. Osong Public Health Res Perspect 2020;11:85-90.

4. Coronavirus disease (COVID-2019) situation reports. World Health Organization, 2020. [cited 2020 Apr 19]. URL: https://www.who.int/ emergencies/diseases/novel-coronavirus-2019/situation-reports/.

5. Xiang YT, Yang Y, Li W, et al. Timely mental health care for the 2019 novel coronavirus outbreak is urgently needed. Lancet Psychiatry 2020; 7:228-229.

6. Neto MLR, Almeida HG, Esmeraldo JD, et al. When health professionals look death in the eye: the mental health of professionals who deal daily with the 2019 coronavirus outbreak. Psychiatry Res 2020;288: 112972 .

7. The Lancet. COVID-19: protecting health-care workers. Lancet 2020; 395:922.
8. Duan L, Zhu G. Psychological interventions for people affected by the COVID-19 epidemic. Lancet Psychiatry 2020;7:300-302.

9. Kang $\mathrm{L}, \mathrm{Li} \mathrm{Y}, \mathrm{Hu}$ S, et al. The mental health of medical workers in Wuhan, China dealing with the 2019 novel coronavirus. Lancet Psychiatry 2020;7:e14.

10. Beck AT, Steer RA, Brown GK. BDI-II: Beck depression inventory manual. 2nd ed. San Antonio: Psychological Corporation, 1996;490-498.

11. Lim SY, Lee EJ, Jeong SW, et al. The validation study of Beck depression scale 2 in Korean version. Anxiety and Mood 2011;7:48-53.

12. Beck AT, Epstein N, Brown G, Steer RA. An inventory for measuring clinical anxiety: psychometric properties. J Consult Clin Psychol 1988; 56:893-897.

13. Yook SP, Kim ZS. A clinical study on the Korean version of Beck anxiety inventory: comparative study of patient and non-patient. Kor J Clin Psychol 1997;16:185-197.

14. Buysse DJ, Ancoli-Israel S, Edinger JD, Lichstein KL, Morin CM. Recommendations for a standard research assessment of insomnia. Sleep 2006;29:1155-1173.

15. Sohn SI, Kim DH, Lee MY, Cho YW. The reliability and validity of the Korean version of the Pittsburgh sleep quality index. Sleep Breath 2012; 16:803-812.

16. Chua SE, Cheung V, Cheung C, et al. Psychological effects of the SARS outbreak in Hong Kong on high-risk health care workers. Can J Psychiatry 2004;49:391-393.

17. Lee SM, Kang WS, Cho AR, Kim T, Park JK. Psychological impact of the 2015 MERS outbreak on hospital workers and quarantined hemodialysis patients. Compr Psychiatry 2018;87:123-127.

18. Lai J, Ma S, Wang Y, et al. Factors associated with mental health outcomes among health care workers exposed to coronavirus disease 2019. JAMA Netw Open 2020;3:e203976.

19. Wong TW, Yau JK, Chan CL, et al. The psychological impact of severe acute respiratory syndrome outbreak on healthcare workers in emergency departments and how they cope. Eur J Emerg Med 2005;12:13-18.

20. Shih FJ, Gau ML, Kao CC, et al. Dying and caring on the edge: Taiwan's surviving nurses' reflections on taking care of patients with severe acute respiratory syndrome. Appl Nurs Res 2007;20:171-180.

21. Mok E, Chung BP, Chung JW, Wong TK. An exploratory study of nurses suffering from severe acute respiratory syndrome (SARS). Int $J$ Nurs Pract 2005;11:150-160. 